\title{
Emodin inhibits angiogenesis in pancreatic cancer by regulating the transforming growth factor- $\beta /$ drosophila mothers against decapentaplegic pathway and angiogenesis-associated microRNAs
}

\author{
SHENG-ZHANG LIN ${ }^{1}$, JIN-BO XU $^{2}, \mathrm{XU} \mathrm{J}^{3}$, HUI CHEN ${ }^{4}$, HONG-TAO XU ${ }^{2}$, PING HU $^{2}$, LIANG CHEN $^{4}$, \\ JING-QIANG GUO ${ }^{4}$, MIN-YUAN CHEN $^{4}$, DIAN LU $^{4}$, ZHAO-HONG WANG ${ }^{4}$ and HONG-FEI TONG ${ }^{4}$ \\ ${ }^{1}$ Department of Hepatobiliary-Pancreatic Surgery, First Affiliated Hospital, Zhejiang University School of Medicine, \\ Hangzhou, Zheijiang 310003; ${ }^{2}$ Department of General Surgery, Central Hospital of Lishui, Lishui, Zhejiang 323000; \\ ${ }^{3}$ Department of Gastrointestinal Surgery, Zhejiang Provincial People's Hospital, Hangzhou, Zheijiang 310014; \\ ${ }^{4}$ Department of Hepatobiliary-Pancreatic Surgery, The Second Affiliated Hospital of Wenzhou Medical University, \\ Wenzhou, Zheijiang 325027, P.R. China
}

Received May 21, 2014; Accepted February 17, 2015

DOI: $10.3892 / \mathrm{mmr} .2015 .4158$

\begin{abstract}
Emodin is a traditional Chinese medicine, which has been demonstrated to inhibit the growth of pancreatic cancer cells. However, the underlying molecular mechanisms remain to be elucidated. The present study investigated whether emodin suppresses angiogenesis in pancreatic cancer. A nude mouse pancreatic cancer xenograft model was established using SW1990 human pancreatic cancer cells by surgical orthotopic implantation. Different doses of emodin were injected into the abdominal cavities of the tumor-bearing mouse models and controls three times each week for 2 weeks. The tumors were measured and weighed, the expression of cluster of differentiation 34 was detected using immunochemistry, and microvessel densities were calculated. Reverse transcription-quantitative polymerase chain reaction (RT-qPCR) and western blotting were performed to determine the mRNA and protein expression levels of transforming growth factor (TGF)- $\beta$ and drosophila mothers against decapentaplegic (Smad) homologs. The angiogenesis-associated microRNAs (miR), miR-20, miR-155 and miR-210 were assessed by RT-qPCR. A negative dose-dependent association was revealed between treatment with emodin and the volume and weight of tumors and microvessel density. Emodin was associated with lower mRNA and protein expression levels of TGF- $\beta 1$ and its downstream target, angiopoietin-like 4, and higher mRNA and
\end{abstract}

Correspondence to: Professor Sheng-Zhang Lin, Department of Hepatobiliary-Pancreatic Surgery, First Affiliated Hospital, Zhejiang University School of Medicine, 79 Qingchun Road, Hangzhou, Zheijiang 310003, P.R. China

E-mail: wzf21sz@163.com

Key words: emodin, pancreatic cancer, angiogenesis, transforming growth factor- $\beta /$ drosophila mother against decapentaplegic homolog, microRNA protein expression levels of TGF- $\beta$ receptor (T $\beta$ R)I, T $\beta$ RII and Smad4. Notably, treatment with emodin was associated with lower expression levels of miR-155 and miR-210 and higher expression levels of miR-20b. The present study suggested that treatment with emodin may repress angiogenesis in pancreatic cancer by altering the activities of the TGF- $\beta /$ Smad pathway and angiogenesis-associated miR-20b, miR-155, and miR-210.

\section{Introduction}

Pancreatic cancer is an exocrine gland neoplasm of the pancreas. It is the most prevalent type of malignant tumor of the digestive system and isthe fourth most prevalent of all types of malignant tumor(1). Due to the depth and concealed position of the pancreas in the retroperitoneum, the majority of cases of pancreatic cancer are diagnosed at late stages with distant metastases. Significant advances have been made in understanding the biology and therapeutics of pancreatic cancer, however the 5-year survival rate remains $<6 \%(1,2)$. Surgery increases the survival rate, however, surgery is only suitable for $10-15 \%$ of patients as metastasis is usually already present at diagnosis (3).

Systemic chemotherapy is the major treatment approach for $85 \%$ of patients with advanced pancreatic cancer (3). Gemcitabine is the standard chemotherapeutic agent for late stage pancreatic cancer (4), however, its curative effect is limited. The median survival rate following radical surgery with adjunct gemcitabine treatment is only 22.1 months (5). In addition, a number of patients with pancreatic cancer develop resistance to gemcitabine. Gemcitabine, in combination with fluorouracil, cisplatin, oxaliplatin and capecitabine, can somewhat improve the survival rates of patients with advanced disease, however, the median survival rate remains between 6.5 and 9.4 months (6-10). Therefore, novel and effective therapeutic strategies are urgently required for the treatment of advanced pancreatic cancer.

Emodin is an anthraquinone drug, which has been demonstrated to induce apoptosis and inhibit the growth 
and metastasis of various types of malignant tumor. Its low toxicity has been demonstrated in vivo and in vitro (11-13). A previous study indicated that emodin may inhibit angiogenesis in pancreatic cancer (14), however, the underlying molecular mechanisms remain to be elucidated. In the present study, the anti-angiogenesis effects of emodin were investigated in a mouse xenograft pancreatic cancer model. Changes in the tumor angiogenesis-associated transforming growth factor (TGF)- $\beta$ /drosophila mothers against decapentaplegic (Smad) pathways and in the expression levels of microRNAs (miR), including miR-20b, miR-155 and miR-210, were examined.

\section{Materials and methods}

Reagents. Emodin was purchased from Sigma-Aldrich (St. Louis, MO, USA), dissolved in dimethyl sulfoxide (DMSO; Sigma-Aldrich) at $0.2 \mathrm{mmol} / 1$ as a stock solution and stored at $-20^{\circ} \mathrm{C}$. The final concentration of DMSO was $<0.1 \%$. A mouse polyclonal anti-cluster of differentiation (CD)34 antibody (cat. no. sc-74499), mouse polyclonal anti-TGF $\beta$ receptor (T $\beta$ R)II antibody (cat. no. sc-17799), mouse monoclonal anti-Smad4 antibody (cat. no. sc-7966) and goat polyclonal anti-angiopoietin-like (Angptl)4 antibody (cat. no. sc-34113) were purchased from Santa Cruz Biotechnology, Inc. (Santa Cruz, CA, USA). A rabbit polyclonal anti-TGF- $\beta 1$ antibody (cat. no. ab92486) and rabbit polyclonal anti-T $\beta$ RI antibody (cat. no. ab31013) were purchased from Abcam (Cambridge, MA, USA). TRIzol ${ }^{\circledR}$ reagent was purchased from Invitrogen Life Technologies (Carlsbad, CA, USA). The RevertAid First Strand cDNA Synthesis kit was purchased from Fermentas (Burlington, ON, Canada). The Takara One Step PrimeScript miRNA cDNA Synthesis kit (Perfect Real Time) and Takara SYBR Premix ExTaq ${ }^{\mathrm{TM}}$ II (Perfect Real Time) were purchased from Takara Bio, Inc. (Otsu, Japan). The study was approved by the Ethics Committee of First Affiliated Hospital, Zhejiang University School of Medicine (Hangzhou, China).

Cell line. The SW1990 human pancreatic cancer cell line was purchased from the American Type Culture Collection (Manassas, VA, USA) and cultured in RPMI-1640 medium (Invitrogen Life Technologies), supplemented with $10 \%$ heat-incubated fetal bovine serum (Invitrogen Life Technologies), $100 \mathrm{U} / \mathrm{ml}$ penicillin and $100 \mathrm{mg} / \mathrm{ml}$ streptomycin (Beyotime Institute of Biotechnology, Shanghai, China) at $37^{\circ} \mathrm{C}$ in a humidified $5 \% \mathrm{CO}_{2}$ atmosphere. The cells were passaged at $70-80 \%$ confluence.

Animals. Female athymic BALB/c nu/nu mice (4-6-weeks old, weighing 20-22 g) were purchased from the Shanghai Cancer Institute for Tumor Implantation (Shanghai, China). The animals were maintained in a sterile environment maintained at room temperature $\left(25^{\circ} \mathrm{C}\right)$ and $60-65 \%$ relative humidity, with ad libitum provision of water at the Animal Experiment Center of Zhejiang University School of Medicine (Zheizhang. China).

Orthotopic implantation of pancreatic cancer and treatment. A total of $2 \times 10^{6}$ SW1990 cells were subcutaneously injected into the flanks of donor nude mice. At a volume of $1 \mathrm{~cm}^{3}$, the subcutaneous tumor was removed under sterile conditions. The central necrotic tissues in the tumor were removed and the healthy peripheral tissue from the subcutaneous tumor was cut into tissue blocks of $1 \mathrm{~mm}^{3}$ for orthotopic transplantation. Recipient nude mice $(\mathrm{n}=40)$ were anesthetized with pelltobarbitalum natricum (50 mg/kg; Sigma-Aldrich) and opened via a left longitudinal laparotomy. The spleen and the pancreatic tail were gently exteriorized, and a tissue pocket in the pancreatic parenchyma was created using micro-scissors (Santa Cruz Biotechnology, Inc.). A tumor fragment $\left(\sim 1 \mathrm{~mm}^{3}\right)$ was placed into the tissue pocket, ensuring that it was entirely surrounded by normal pancreatic tissue. Following careful relocation of the pancreas and spleen into the abdominal cavity, the cavity was closed in two layers using 4-0 silk sutures for the muscular layer and nonabsorbable stainless steel wound clips for the skin.

Following a recovery period of 3 weeks, the in situ xenograft model of pancreatic cancer was complete and the mice were randomly divided into four groups, termed the control, E20, E40 and E80 group, each containing 10 mice. The mice in the control group were each injected with $0.2 \mathrm{ml} 0.9 \%$ sodium chloride (Shanghai Chemical Reagent Plant, Shanghai,China) into the abdominal cavity. The mice in the E20, E40 and E80 groups were injected with 20, 40 and $80 \mathrm{mg} / \mathrm{kg}$ emodin, respectively, using the same method as the control (15). Each group was treated three times each week for 2 weeks. The mice were euthanized 7 weeks after implantation by cervical dislocation and the pancreatic tumors were carefully separated and weighed (scales from Mettler-Toledo International, Inc., Zurich, Switzerland). The orthotopic tumor tissues were then either stored in $4 \%$ paraformaldehyde (Shanghai Chemical Reagent Plant) for immunohistochemistry or were frozen in liquid nitrogen.

CD34 immunohistochemistry and calculation of microvessel density. The tissue sections were cut from the paraffin-embedded pancreatic cancer tissues, blocked with goat serum (Zhejiang Tianhang Biological Technology Co., Ltd., Hangzhou, China) and immunostained following deparaffinization with xylene for $10 \mathrm{~min}$ and rehydration with ethanol for 5 min 3 times. Immunostaining was performed using primary antibodies specific for CD34 (1:50) at room temperature for $60 \mathrm{~min}$, followed by staining with horseradish peroxidase-conjugated secondary antibodies $(1: 1,500)$ at room temperature for $30 \mathrm{~min}$. The slides were developed in diaminobenzidine (Beyotime Institute of Biotechnology) and counterstained with hematoxylin (Beyotime Institute of Biotechnology). The stained slides were dehydrated and mounted in Permount (Beyotime Institute of Biotechnology) and visualized under a light microscope (Olympus, Tokyo, Japan). Images were captured using an attached camera linked to a computer. The slides were visualized for the identification of clusters of microvessels under low power (magnification, x100). Random visual fields $(n=5)$ were selected for inspection under high power (magnification, $\mathrm{x} 400$ ). The number of CD34-positive cells in each visual field was defined as the microvessel density (16-18).

Detecting the mRNA expression levels of TGF- $\beta 1, T \beta R I, T \beta R I I$, Smad4 and Angptl4 via reverse transcription-quantitative polymerase chain reaction $(R T-q P C R)$. The total RNA in the tumor tissues was extracted using TRIzol reagent, according to the manufacturer's instructions, and quantified 
Table I. Primers used in the quantitative polymerase chain reaction.

\begin{tabular}{|c|c|c|}
\hline Gene & Primer $\left(5^{\prime}-3^{\prime}\right)$ & Product length (bp) \\
\hline TGF- $\beta 1$ & $\begin{array}{l}\text { Forward: CAATTCCTGGCGATACCTCAG } \\
\text { Reverse: GCACAACTCCGGTGACATCAA }\end{array}$ & 86 \\
\hline $\mathrm{T} \beta \mathrm{RI}$ & $\begin{array}{l}\text { Forward: GCTGTATTGCAGACTTAGGACTG } \\
\text { Reverse: TTTTTGTTCCCACTCTGTGGTT }\end{array}$ & 90 \\
\hline $\mathrm{T} \beta \mathrm{RII}$ & $\begin{array}{l}\text { Forward: AAGATGACCGCTCTGACATCA } \\
\text { Reverse: CTTATAGACCTCAGCAAAGCGAC }\end{array}$ & 119 \\
\hline Smad4 & $\begin{array}{l}\text { Forward: CCACCAAGTAATCGTGCATCG } \\
\text { Reverse: TGGTAGCATTAGACTCAGATGGG }\end{array}$ & 76 \\
\hline Angptl4 & $\begin{array}{l}\text { Forward: GGCTCAGTGGACTTCAACCG } \\
\text { Reverse: CCGTGATGCTATGCACCTTCT }\end{array}$ & 103 \\
\hline$\beta$-actin & $\begin{array}{l}\text { Forward: CATTGCCGACAGGATGCAG } \\
\text { Reverse: CTCGTCATACTCCTGCTTGCTG }\end{array}$ & 169 \\
\hline
\end{tabular}

TGF, transforming growth factor; T $\beta$ R, TGF- $\beta$ receptor; Smad, drosophila mothers against decapentaplegic; Angptl, angiopoietin-like; bp, base pairs.

by spectrophotometric analysis (RF-5301PC; Shimadzu Corporation, Kyoto, Japan). The RNA integrity was verified using agarose gel electrophoresis. cDNA was synthesized using a RevertAid First Strand cDNA Synthesis kit (Fermentas), a random primer ( $\beta$-actin) and $1 \mathrm{mg}$ RNA. The cDNA product was diluted 1:4 into deionized water. The cDNA, primers specific for TGF- $\beta 1$, T $\beta$ RI, T $\beta$ RII, Smad4, Angptl4 and $\beta$-actin (Table I), and Sybr Green I mix were added to a $20 \mu \mathrm{l}$ reaction volume, supplemented with deionized water, according to the manufacturer's instructions. The PCR was performed using a Roche real-time PCR system (Roche Diagnostics, Basel, Switzerland) and the data were analyzed using LightCycler 480 software (Roche Diagnostics). $\beta$-actin was used an internal control. The conditions for the PCR reactions were as follows: Denaturation at $94^{\circ} \mathrm{C}$ for $30 \mathrm{sec}$, annealing at $60^{\circ} \mathrm{C}$ for $30 \mathrm{sec}$ and extension at $72^{\circ} \mathrm{C}$ for $60 \mathrm{sec}$ for up to 40 cycles.

microRNA RT-qPCR. To determine the expression levels of miR, the cDNA was synthesized using a Takara One Step PrimeScript miRNA cDNA Synthesis kit (Takara Bio, Inc.), using an miRPrimeScript RT Enzyme mix (Takara Bio, Inc.) and $1 \mathrm{mg}$ RNA. The cDNA product was diluted to 1:4 in deionized water and the cDNA, primers specific to miR-20, miR-155 and miR-210, or the U6B control, and the SYBR Premix Ex TaqII were added to a $20 \mu 1$ reaction volume, supplemented with deionized water, according to the manufacturer's instructions. The PCR was performed using a LightCycler Real Time PCR 480 system. The primers used were as follows: miR-20b, 5'-CAAAGUGCUCAUAGUGCAGGUAG-3', miR-210, 5'-AGCCCCUGCCCACCGCACACUG-3' and miR-155, 5'-UUAAUGCUAAUCGUGAUAGGGGU-3'.

Western blotting. The total proteins were routinely extracted from the tumor tissues using radioimmunoprecipitation lysis buffer (containing $50 \mathrm{mM}$ Tris, $\mathrm{pH} 7.4 ; 150 \mathrm{mM} \mathrm{NaCl}, 1 \%$ Triton $\mathrm{X}-100,1 \%$ sodium deoxycholate, and $0.1 \%$ SDS, sodium orthovanadate, sodium fluoride, EDTA and leupeptin;
Beyotime Institute of Biotechnology) and the protein concentrations were determined using a bicinchoninic acid assay (Thermo Fisher Scientific, Waltham, MA, USA). The proteins were separated on 12\% SDS-PAGE gels (Bio-Rad Laboratories, Inc., Shanghai, China), electrotransferred onto polyvinylidene fluoride membranes (Invitrogen Life Technologies), blocked with 5\% non-fat milk (Yili, Inc., Inner Mongolia, China) and subsequently probed with primary antibodies (anti-TGF- $\beta 1$, anti-T $\beta$ RI and anti-GAPDH at a dilution of 1:1,000, anti-Smad4 at a dilution of 1:800, and anti-T $\beta$ RII and anti-Angptl4 at a dilution of 1:500) and horseradish peroxidase-conjugated secondary antibody (at a dilution of 1:10,000). Following washing with Tris-buffered saline with Tween 20 (Beyotime Institute of Biotechnology), the bound antibody complexes were analyzed using an enhanced chemiluminescence reagent (Amersham Pharmacia Biotech., Piscataway, NJ, USA). A GAPDH antibody (anti-rabbit GAPDH; cat. no. AB-P-R 001; Hangzhou Goodhere Biotechnology Co., Ltd., Hangzhou, China) was used as the control.

Statistical analysis. TotalLab 2.1 software (TotalLab, Ltd., Newcastle, UK) was used to analyze the western blots, and LightCycler 480 software V1.5.0 was used to analyze the RT-qPCR data. The images presented are representative and data are expressed as the mean \pm standard error of the mean of each group. Differences between groups of cells or mice were analyzed using analysis of variance and Student's post-hoc t-test using SPSS 17.0 software (SPSS, Inc., Chicago, IL, USA). $\mathrm{P}<0.05$ was considered to indicate a statistically significant difference.

\section{Results}

Emodin inhibits the growth of orthotopically transplanted pancreatic cancer. The tumor weights were measured 7 days after the final treatment og different doses of emodin (Fig. 1 and Table II). The tumor weights of the E40 and 

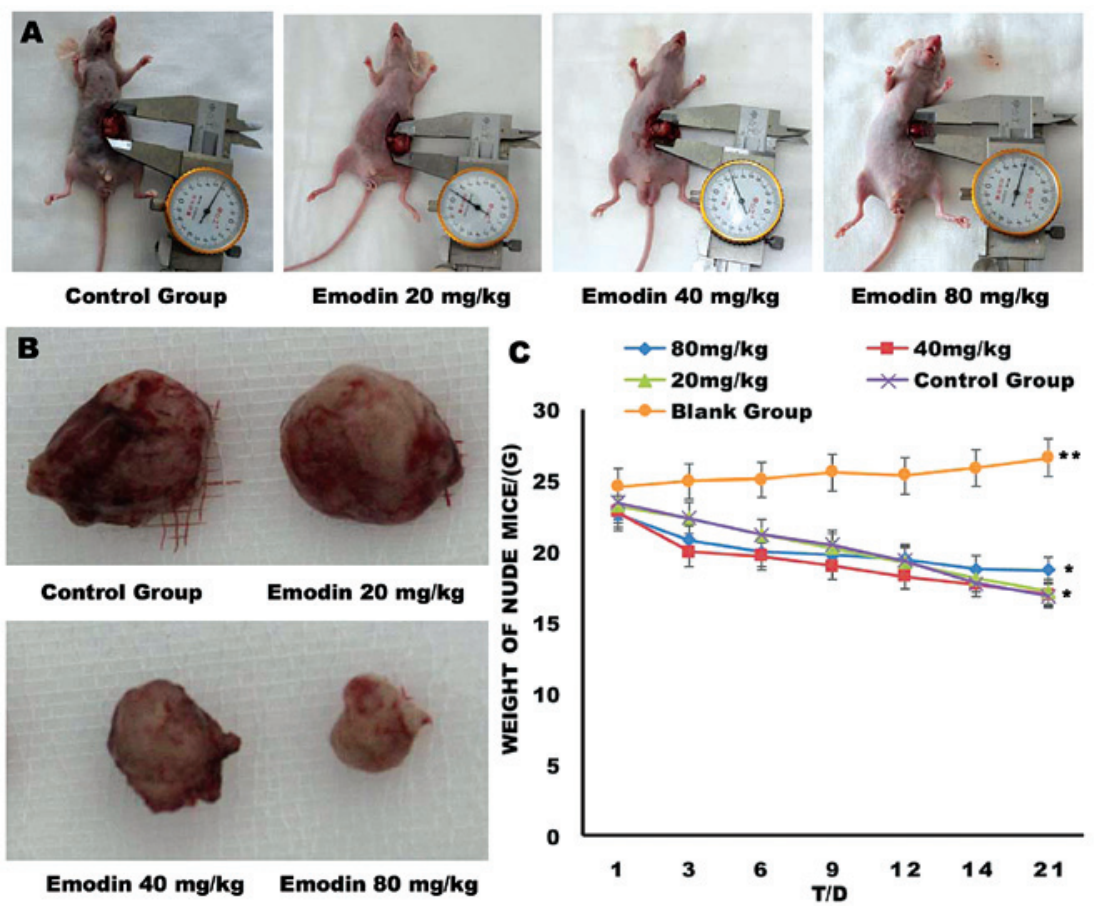

Figure 1. Pancreatic tumors. (A) Representative tumors from a mouse from each of the four treatment groups. (B) Orthotopically implanted pancreatic tumors on day 21 following treatment. The tumor diameters in the E40 and E80 groups were significantly lower compared with those from the untreated control. (C) Weights of the mice during the treatment period. Blank group contained healthy mice, which did not undergo transplant surgery. Data are expressed as the mean \pm standard error of the mean. ${ }^{*} \mathrm{P}<0.05,{ }^{* * *} \mathrm{P}<0.01$ vs. control group. $\mathrm{T} / \mathrm{D}$, time (days).

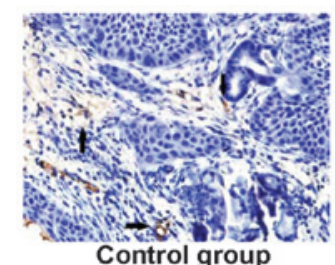

Control group

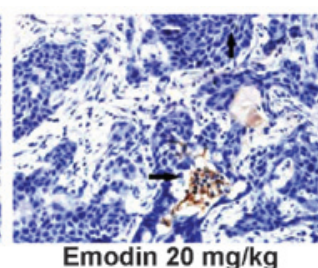

Emodin $20 \mathrm{mg} / \mathrm{kg}$

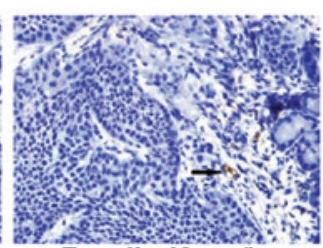

Emodin $40 \mathrm{mg} / \mathrm{kg}$

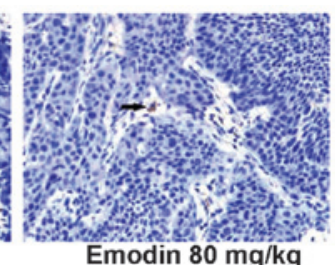

Emodin $80 \mathrm{mg} / \mathrm{kg}$

Figure 2. Expression of CD34 detected by immunohistochemistry (magnification, $\mathrm{x} 400$ ). The mean optical densities of CD34 were determined in the orthotopic transplanted tumor tissues from the mice following treatment without (control) or with different doses of Emodin. CD, cluster of differentiation.

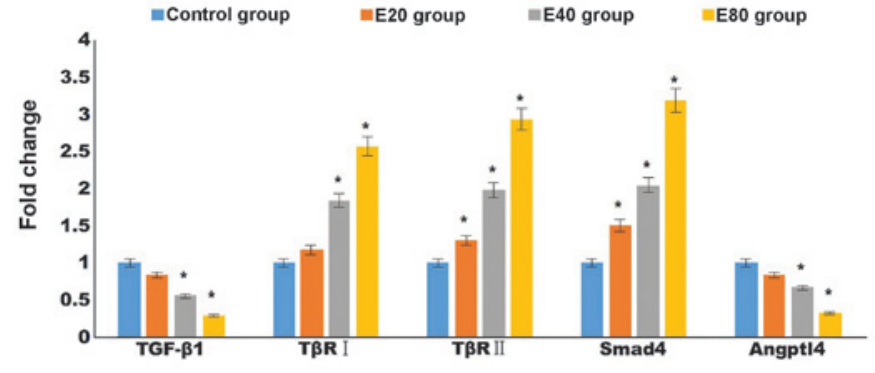

Figure 3. Treatment with emodin led to changes in the mRNA expression levels of angiogenesis-associated TGF- $\beta 1, T \beta R I, T \beta R I I$, Smad4 and Angpt14. Data are expressed as the mean \pm standard error of the mean. $\mathrm{P}<0.05$ vs. control group. TGF, transforming growth factor; T $\beta$ R, TGF- $\beta$ receptor; Smad, drosophila mothers against decapentaplegic; Angptl, angiopoietin-like.

E80 groups were significantly lower compared with those of the control and E20 groups $(\mathrm{P}<0.05)$. No significant difference in mean tumor weight was observed between the control and E20 groups ( $\mathrm{P}>0.05)$. Therefore, tumor growth was effectively inhibited in the tumor-bearing mice following treatment with $40 \mathrm{mg} / \mathrm{kg}$ emodin.
Emodin significantly reduces the angiogenesis of orthotopically transplanted pancreatic cancer. To determine whether treatment with emodin inhibited the angiogenesis of pancreatic cancer, the numbers of CD34-positive cells and the microvessel density were calculated by immunohistochemistry (Fig. 2 and Table III). The microvessels were significantly less dense in the E20, E40 and E80 groups compared with the control group. Additionally, treatment of tumor-bearing mice with $20 \mathrm{mg} / \mathrm{kg}$ emodin significantly reduced microvessel density.

Emodin decreases the MRNA expression levels of TGF- $\beta I$ and Angptl4 and increases the mRNA expression levels of TRRI, TRRII and Smad4. To examine the mechanisms by which emodin inhibits the angiogenesis of pancreatic cancer, the gene expression levels of the TGF- $\beta$ I, T $\beta$ RI, T $\beta$ RII, Smad4 and Angptl4 angiogenesis-associated genes were determined. Treatment with emodin decreased the mRNA expression levels of TGF- $\beta 1$ and Angptl4 in a dose-dependent manner, and the expression levels were significantly lower in the E40 and E80 groups compared with those of the control group $(\mathrm{P}<0.05)$. In addition, treatment with emodin increased the mRNA expression levels of T $\beta$ RI, T $\beta$ RII and Smad4. The expression levels 


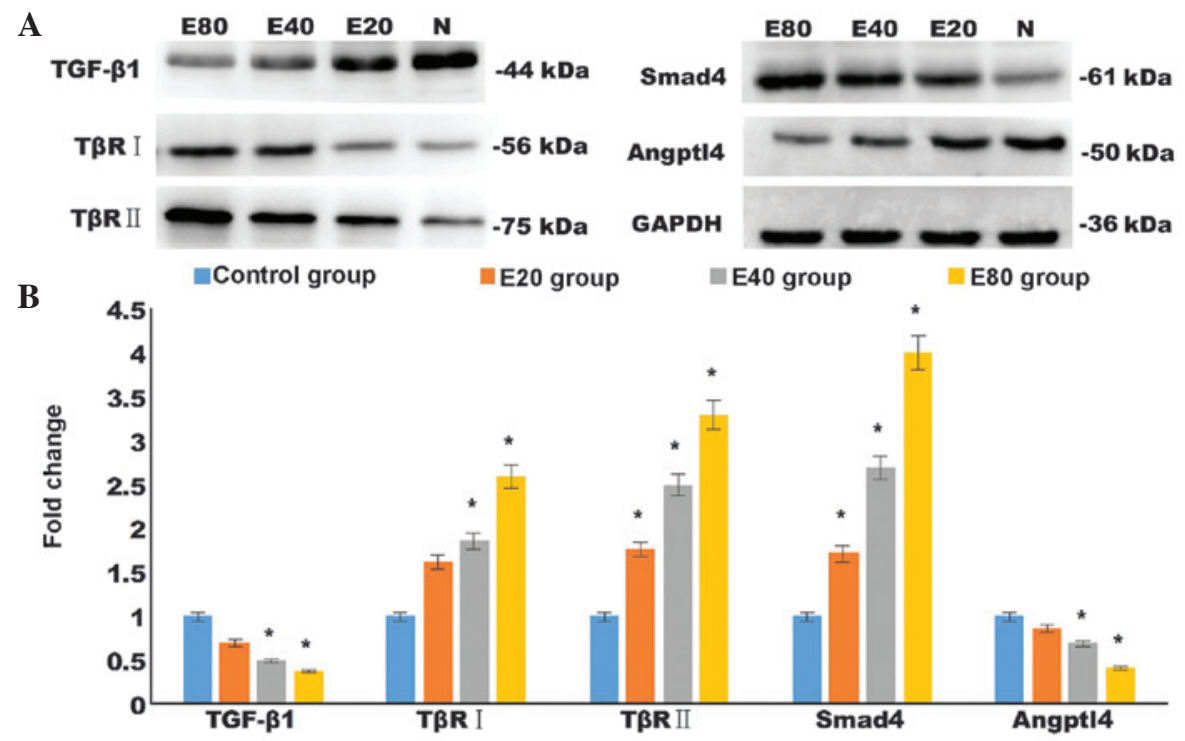

Figure 4. Emodin altered the protein expression levels of angiogenesis-associated TGF- $\beta 1$, T $\beta$ RI, T $\beta$ RII, Smad4, and Angpt14. (A) Protein expression levels of TGF- $\beta 1$, T $\beta R I$, T $\beta$ RII, Smad4 and Angpt14 in tumor tissues was detected by western blotting. (B) Quantified data from the western blotting. Data are expressed as the mean \pm standard error of the mean. "P<0.05, compared with the control group. TGF, transforming growth factor; T $\beta R$, TGF- $\beta$ receptor; Smad, drosophila mothers against decapentaplegic; Angptl, angiopoietin-like.

Table II. Weight of orthotopically implanted pancreatic tumors on day 21 following treatment with emodin.

\begin{tabular}{lcc}
\hline Group & Tumor weight $(\mathrm{g})$ & Inhibition rate $^{\mathrm{a}}(\%)$ \\
\hline Control & $1.671 \pm 0.289$ & 0 \\
E20 & $1.487 \pm 0.248$ & 11.0 \\
E40 & $1.172 \pm 0.205^{\mathrm{b}}$ & 29.8 \\
E80 & $0.741 \pm 0.210^{\mathrm{b}}$ & 55.6 \\
\hline
\end{tabular}

anhibition rate of tumor $=(1-$ average weight of emodin group/average weight of the control group) $x 100 \%$; ${ }^{b}$ statistical significant $(\mathrm{P}<0.05)$.

Table III. Emodin reduced microvessel density of orthotopically transplanted pancreatic cancer.

\begin{tabular}{lc}
\hline Group & Microvessel density \\
\hline Control & $16.5 \pm 1.1$ \\
E20 & $12.3 \pm 1.8^{\mathrm{a}}$ \\
E40 & $5.4 \pm 1.6^{\mathrm{a}}$ \\
E80 & $4.8 \pm 1.6^{\mathrm{a}}$ \\
\hline
\end{tabular}

${ }^{\mathrm{a}} \mathrm{P}<0.05$.

of T $\beta$ RI were significantly higher in the E40 and E80 groups compared with the control group $(\mathrm{P}<0.05)$ and the expression levels of T $\beta$ RII and Smad4 were significantly higher in the E20, E40 and E80 groups ( $\mathrm{P}<0.05$ and Fig. 3).

Emodin decreases the protein expression levels of TGF- $\beta$ I and Angptl4, and increases the expression levels of T $\beta R I, T \beta R I I$

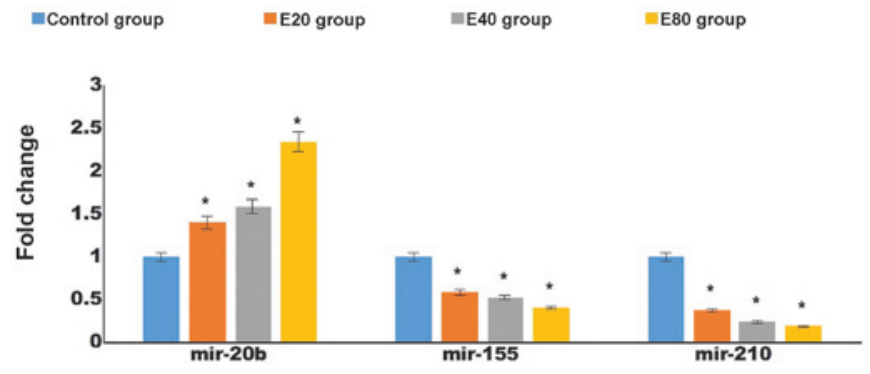

Figure 5. Emodin altered the expression levels of angiogenesis-associated mir-155, mir-210 and mir-20b. Quantitative results from reverse transcription-quantitative polymerase chain reaction. Data are expressed as the mean \pm standard error of the mean. ${ }^{*} \mathrm{P}<0.05$, compared with the control group). mir, microRNA.

and Smad4. Consistent with the differences in the mRNA expression levels, the results of the western blotting demonstrated that different doses of emodin upregulated the protein expression levels of T $\beta$ RII and Smad4 compared with control group in the pancreatic cancer tissues $(\mathrm{P}<0.05)$. Similarly, emodin increased the protein expression of T $\beta R I$ compared with the control group with significant differences between the E40 and E80 group, and the control group $(\mathrm{P}<0.05)$. Treatment with emodin also downregulated the protein expression levels of TGF- $\beta 1$ and Angptl4 compared with the control group in the pancreatic cancer tissues, with significant differences between the E40 and E80 group, and the control group ( $\mathrm{P}<0.05$; Fig. 4).

Effect of emodin on the expression levels of angiogenesis-associated miR-155, miR-210 and miR-20b in pancreatic cancer tissues. miRNAs have been found to be important in angiogenesis. To determine whether emodin affects the expression levels of angiogenesis-associated miRNAs in pancreatic cancer tissues, the expression levels of miR-155, miR-210 and miR-20b were assessed by RT-qPCR. The levels of miR-20b in the pancreatic cancer tissues were higher in the groups treated 
with emodin $(\mathrm{P}<0.05)$, whereas those of miR-155 and miR-210 were lower compared with the control group. These changes occurred in a dose-dependent manner $(\mathrm{P}<0.05$; Fig. 5).

\section{Discussion}

The tumor microenvironment is important during tumorigenesis. Sustained angiogenesis is a hallmark of cancer and is key to the metastasis of cancer cells. Initial tumor growth depends on the original blood vascular system, however, when the tumor is $>1-2 \mathrm{~mm}^{3}$, the nutrients supplied by the existing blood vessels are not sufficient to sustain further tumor growth, requiring the production of new vessels through the process of angiogenesis (19). In as early as in 1971, Folkman (18) suggested that the growth of tumor cells was dependent on angiogenesis.

In the present study, treatment with emodin was observed to inhibit the growth of pancreatic cancer in a dose-dependent manner. Multiple previous studies have revealed that emodin can inhibit the proliferation of vascular endothelial cells $(21,22)$. To assess the anti-angiogenic properties of emodin in a pancreatic xenograft tumor model, changes in microvascular density following treatment with emodin were determined. The microvessel densities of the emodin-treated groups were significantly lower compared with the control group, consistent with a previous report that emodin inhibited pancreatic cancer-associated angiogenesis (14). These data suggested that the suppression of angiogenesis may be a mechanism by which emodin inhibits tumor growth.

The TGF- $\beta /$ Smad pathway is an antitumor signaling pathway, which is deregulated in several types of cancer $(23,24)$. In the early stages of tumorigenesis, TGF- $\beta$ inhibits cell proliferation, promotes cell differentiation and induces cell apoptosis and, as tumorigenesis progresses, TGF- $\beta$ inhibits immunologic function, increases angiogenesis and promotes invasion of the tumor (25). TGF- $\beta$ binds to and activates T $\beta R I I$ and T $\beta R I$, which in turn phosphorylates the Smad transcription factors. The phosphorylated Smads translocate to the cell nucleus to regulate a series of gene transcription events (24). Our previous study demonstrated that mutations in T $\beta R I$ and T $\beta$ RII promoted tumor angiogenesis and cancer cell proliferation in several types of cancer, including pancreatic, gall bladder, breast and rectal cancer (26). The Smad protein family is the key component of the TGF- $\beta$ signaling pathway. Deregulation of the TGF- $\beta /$ Smad signaling pathways has been observed in $>50 \%$ of pancreatic cancer cases, via mutations in the Smad genes, predominantly Smad 4 , or in genes of the TGF- $\beta$ superfamily and its receptor (27). Similar to mutations in Kirsten rat sarcoma viral oncogene, tumor protein p53 and cyclin-dependent kinase inhibitor $2 \mathrm{~A}, \sim 50 \%$ of the cases of pancreatic cancer exhibit mutated Smad4 (28), however, inactivation mutation in the Smad4 gene usually occurs at a later stage of tumorigenesis. It has been observed that TGF- $\beta$ activates the expression of Angptl4 in tumor cells in the circulation through the Smad signaling pathways (29). Angptl4 is secreted from tumor cells, breaks the conjunction of endothelial cells and subsequently increases capillary permeability (29). The present study revealed that treatment with emodin downregulated the expression levels of TGF- $\beta 1$ and Angpt14, and upregulated the expression levels of the T $\beta R I$ and T $\beta$ RII TGF- $\beta 1$ receptors and Smad4 in the orthotopically implanted pancreatic tumor mouse models. These results suggested that emodin may inhibit angiogenesis by inhibiting the expression levels of TGF- $\beta 1$ and, therefore, inhibiting the secretion of Angpt14 via Smad4.

MicroRNAs are small endogenous non-coding single-chain RNAs. The miRNA gene family occupies $\sim 1 \%$ of the human genome and regulates the expression levels of around one third of human genes. MicroRNAs can also function as oncogenes or tumor suppressor genes. It has been demonstrated that the angiogenesis, which is associated with pancreatic cancer is regulated by microRNAs (30), and miR-20b, miR-155 and miR-210 are among the most extensively investigated of the angiogenesis-associated miRNAs. miR-155 and miR-210 function as oncogenes in various types of tumor, including breast (31), lung (32) and pancreatic (33) cancer, and clear cell carcinoma of the kidney (34). In the present study, treatment with emodin increased the expression of miR-20b and inhibited the expression levels of miR-155 and miR-210. These results suggested that treatment with emodin inhibited the growth of tumors by suppressing tumor-associated angiogenesis.

In conclusion, using an orthotopically transplanted pancreatic cancer model, it was observed that treatment with emodin inhibited angiogenesis by regulating the TGF- $\beta / \mathrm{Smad}$ signaling pathway and the expression levels of miRNA. These results revealed that emodin inhibits the growth of pancreatic cancer through a variety of different mechanisms (15), suggesting emodin as a promising natural drug for the treatment of pancreatic cancer.

\section{Acknowledgements}

This study was supported by the Animal Experimental Center of Zhejiang University School of Medicine (Zheizhang, China),, the Administration of Traditional Chinese Medicine of Zhengjing Province, China (no. 2011ZZ010), the Zhejiang Provincial Science Fund for Distinguished Young Scholars (no.LR12H280001) and the National Natural Science Foundation of China (nos. 81173606 and 81374020). The authors would like to thank the Research Center at the Second Affiliated Hospital of Wenzhou Medical University for technical assistance.

\section{References}

1. Siegel R, Naishadham D and Jemal A: Cancer statistics, 2013. CA Cancer J Clin 63: 11-30, 2013.

2. Hidalgo M: Pancreatic cancer. N Engl J Med 362: 1605-1617, 2010

3. McCracken M, Olsen M, Chen MS Jr, et al: Cancer incidence, mortality, and associated risk factors among Asian Americans of Chinese, Filipino, Vietnamese, Korean, and Japanese ethnicities. CA Cancer J Clin 57: 190-205, 2007.

4. Tempero MA, Behrman S, Ben-Josef E, et al: Pancreatic adenocarcinoma: Clinical practice guidelines in oncology. J Natl Compr Canc Netw 3: 598-626, 2005.

5. Oettle H, Post S, Neuhaus P, et al: Adjuvant chemotherapy with gemcitabine vs observation in patients undergoing curative-intent resection of pancreatic cancer: A randomized controlled trial. JAMA 297: 267-277, 2007.

6. Reni M, Cordio S, Milandri C, et al: Gemcitabine versus cisplatin, epirubicin, fluorouracil, and gemcitabine in advanced pancreatic cancer: A randomised controlled multicentre phase III trial. Lancet Oncol 6: 369-376, 2005. 
7. Louvet C, Labianca R, Hammel P, et al: Gemcitabine in combination with oxaliplatin compared with gemcitabine alone in locally advanced or metastatic pancreatic cancer: Results of a GERCOR and GISCAD phase III trial. J Clin Oncol 23: 3509-3516, 2005.

8. Rocha Lima CM, Savarese D, Bruckner H, et al: Irinotecan plus gemcitabine induces both radiographic and CA 19-9 tumor marker responses in patients with previously untreated advanced pancreatic cancer. J Clin Oncol 20: 1182-1191, 2002.

9. Heinemann V, Quietzsch D, Gieseler F, et al: Randomized phase III trial of gemcitabine plus cisplatin compared with gemcitabine alone in advanced pancreatic cancer. J Clin Oncol 24: 3946-3952, 2006.

10. Burtness B, Thomas L, Sipples R, et al: Phase II trial of weekly docetaxel/irinotecan combination in advanced pancreatic cancer. Cancer J 13: 257-262, 2007.

11. Su YT, Chang HL, Shyue SK and Hsu SL: Emodin induces apoptosis in human lung adenocarcinoma cells through a reactive oxygen species-dependent mitochondrial signaling pathway. Biochem Pharmacol 70: 229-241, 2005.

12. Lin SY, Lai WW, Ho CC, et al: Emodin induces apoptosis of human tongue squamous cancer SCC-4 cells through reactive oxygen species and mitochondria-dependent pathways. Anticancer Res 29: 327-335, 2009

13. Guo Q, Chen Y, Zhang B, Kang M, Xie Q and Wu Y: Potentiation of the effect of gemcitabine by emodin in pancreatic cancer is associated with survivin inhibition. Biochem Pharmacol 77: 1674-1683, 2009

14. Lin SZ, Wei WT, Chen H, Chen KJ, Tong HF, Wang ZH, Ni ZL, Liu HB, Guo HC and Liu DL: Antitumor activity of emodin against pancreatic cancer depends on its dual role: Promotion of apoptosis and suppression of angiogenesis. PLoS One 7: e42146, 2012.

15. Liu JX, Zhang JH, Li HH, Lai FJ, Chen KJ, Chen H, Luo J, Guo HC, Wang ZH and Lin SZ: Emodin induces Panc-1 cell apoptosis via declining the mitochondrial membrane potential. Oncol Rep 28: 1991-1996, 2012.

16. Weidner N: Current pathologic methods for measuring intratumoral microvessel density within breast carcinoma and other solid tumors. Breast Cancer Res Treat 36: 169-180, 1995.

17. Kato H, Ishikura H, Kawarada Y, Furuya M, Kondo S, Kato H and Yoshiki T: Anti-angiogenic treatment for peritoneal dissemination of pancreas adenocarcinoma: A study using TNP-470. Jpn J Cancer Res 92: 67-73, 2001.

18. Folkman J: Fundamental concepts of the angiogenic process. Curr Mol Med 3: 643-651, 2003.

19. Holash J, Maisonpierre PC, Compton D, et al: Vessel cooption regression, and growth in tumors mediated by angiopoietins and VEGF. Science 284: 1994-1998, 1999.
20. Folkman J: Tumor angiogenesis: Therapeutic implications. N Engl J Med 285: 1182-1186, 1971.

21. Kaneshiro T, Morioka T, Inamine M, Kinjo T, Arakaki J, Chiba I, Sunagawa N, Suzui M and Yoshimi N: Anthraquinone derivative emodin inhibits tumor-associated angiogenesis through inhibition of extracellular signal-regulated kinase $1 / 2$ phosphorylation. Eur J Pharmacol 553: 46-53, 2006.

22. Kimura Y, Sumiyoshi M, Taniguchi M and Baba K: Antitumor and antimetastatic actions of anthrone-C-glucoside, cassialoin isolated from Cassia garrettiana heartwood in colon 26-bearing mice. Cancer Sci 99: 2336-2348, 2008.

23. Mansour KA, Fritz RC, Jacobs DM and Vellios F: Pedunculated liposarcoma of the esophagus: A first case report. J Thorac Cardiovase Surg 86: 447-450, 1983.

24. Itoh $\mathrm{S}$ and ten Dijke P: Negative regulation of TGF-beta receptor/Smad signal transduction. Curr Opin Cell Biol 19: 176-184, 2007.

25. Moustakas A and Heldin $\mathrm{CH}$ : Signaling networks guiding epithelial-mesenchymal transitions during embryogenesis and cancer progression. Cancer Sci 98: 1512-1520, 2007.

26. Kang SH, Bang YJ, Im YH, et al: Transcriptional repression of the transforming growth factor-beta type I receptor gene by DNA methylation results in the development of TGF-beta resistance in human gastric cancer. Oncogene 18: 7280-7286, 1999.

27. Miyazono K: TGF-beta/SMAD signaling and its involvement in tumor progression. Biol Pharm Bull 23: 1125-1130, 2000.

28. Jaffee EM, Hruban RH, Canto M and Kern SE: Focus on pancreas cancer. Cancer Cell 2: 25-28, 2002.

29. Padua D, Zhang XH, Wang Q, Nadal C, Gerald WL, Gomis RR and Massagué J: TGFbeta primes breast tumors for lung metastasis seeding through angiopoietin-like 4. Cell 133: 66-77, 2008.

30. Peters BA, Diaz LA, Polyak K, et al: Contribution of bone marrow-derived endothelial cells to human tumor vasculature. Nat Med 11: 261-262, 2005

31. Iorio MV, Ferracin M, Liu CG, et al: MicroRNA gene expression deregulation in human breast cancer. Cancer Res 65: 7065-7070, 2005.

32. Yanaihara N, Caplen N, Bowman E, Seike M, Kumamoto K, Yi M, Stephens RM, Okamoto A, Yokota J, Tanaka T, et al: Unique microRNA molecular profiles in lung cancer diagnosis and prognosis. Cancer Cell 9: 189-198, 2006.

33. Lee EJ, Gusev Y, Jiang J, Nuovo GJ, Lerner MR, Frankel WL, Morgan DL, Postier RG, Brackett DJ and Schmittgen TD: Expression profiling identifies microRNA signature in pancreatic cancer. Int J Cancer 120: 1046-1054, 2007.

34. Juan D, Alexe G, Antes T, Liu H, Madabhushi A, Delisi C, Ganesan S, Bhanot G and Liou LS: Identification of a microRNA panel for clear-cell kidney cancer. Urology 75: 835-841, 2010 